\title{
SENTIDOS PRODUZIDOS POR PROFISSIONAIS DE SAÚDE NA ATENÇÃO A COMUNIDADES QUILOMBOLAS DO VALE DO GUAPORÉ
}

\author{
Meanings Produced by Health Professionals in Attention to Quilombola Communities in the \\ Guaporé Valley
}
Sentidos Producidos por Profesionales de Salud en la Atención a las Comunidades Quilombolas del Vale do Guaporé

\section{Sens Produits par des Professionnels de la Santé dans les Soins aux Communautés Quilombola dans la Vallée du Guaporé}

10.5020/23590777.rs.v20iEsp1.e8745

\section{Eraldo Carlos Batista 9 iD}

Doutor em Psicologia pela Pontifícia Universidade Católica do Rio Grande do Sul. Professor de Psicologia e Filosofia na Universidade Estadual de Mato Grosso (UNEMAT).

\section{Kátia Bones Rocha 9}

Docente de Psicologia da Pontifícia Universidade Católica do Rio Grande do Sul (PUCRS). Doutora em Psicologia pela Universitat Autònoma de Barcelona (UAB), Espanha.

\section{Resumo}

Este artigo tem como objetivo analisar os sentidos produzidos por profissionais de saúde em relação à atenção à saúde em três comunidades quilombolas do Vale do Guaporé, no estado de Rondônia. O recurso metodológico utilizado foi a abordagem qualitativa. A construção do corpus foi realizada a partir de entrevistas semiestruturadas com seis profissionais de saúde e a técnica de análise foi a análise do discurso influenciada pela perspectiva do construcionismo social. Os sentidos produzidos pelos profissionais, apontados por meio de suas falas, permitiram a identificação de quatro repertórios interpretativos: 1) construção social do remanescente quilombola a partir da diferença: cordialidade, atraso e desinteresse; 2) problemas de saúde mental na comunidade; 3) aspectos sociais, culturais e simbólicos da comunidade como práticas de cuidado em saúde mental; e 4) entraves na atenção: distanciamentos teórico-práticos e (i)mobilidades. As reflexões relativas aos discursos ora apresentados apontam para a necessidade de capacitação e de formação continuada dos profissionais em saúde da população negra para que haja uma reflexão crítica da realidade e dos condicionantes sociais inerentes à saúde dessa população.

Palavras-chave: profissional de saúde; comunidade quilombola; saúde pública.

\section{Abstract}

This article aims to analyze the meanings produced by health professionals concerning health care in three Quilombola communities in the Vale do Guaporé, in the state of Rondonia. The methodological resource used was the qualitative approach. The construction of the corpus was carried out from semi-structured interviews with six health professionals and the analysis technique was the analysis of the discourse influenced by the perspective of social constructionism. The meanings produced by the professionals, pointed out through their speeches, allowed the identification of four interpretative repertoires: 1) social construction of the Quilombola remnant from the difference: cordiality, delay, and disinterest; 2) mental health problems in the community; 3) social, cultural and symbolic aspects of the community as mental health care practices, and 4) barriers to attention: theoretical-practical distances and (i) mobility. The reflections on the speeches presented point to the need for training and continuing education of health professionals in the black population so that there is a critical 
reflection on the reality and social conditions inherent to health.

Keywords: health professional; quilombola community; public health.

\section{Resumen}

Este trabajo tiene el objetivo de analizar los sentidos producidos por profesionales de salud en relación a la atención a la salud en tres comunidades quilombolas del Vale do Guaporé, en el estado de Rondônia. El recurso metodológico utilizado fue el enfoque cualitativo. La construcción del corpus fue realizada a partir de entrevistas semiestructuradas con seis profesionales de saludy la técnica de análisis fue el análisis del discurso influenciada por la perspectiva del construccionismo social. Los sentidos producidos por los profesionales, indicados por medio de sus hablas, permitieron la identificación de cuatro repertorios interpretativos: 1) construcción social del restante quilombola a partir de la diferencia; cordialidad, retraso y falta de interés; 2) problemas de salud mental en la comunidad; 3) características sociales, culturales y simbólicos de la comunidad como practicas de cuidado en salud mental; y 4) barreras en la atención: alejamientos teóricoprácticos e (i)movilidades. Las reflexiones relativas a los discursos ya presentados indican la necesidad de capacitación y de formación continuada de los profesionales en salud de la población negra para que haya una reflexión crítica de la realidad y de los condicionantes sociales inherentes a la salud de esta población.

Palabras clave: profesional de salud; comunidad quilombola; salud pública.

\section{Résumé}

Cet article vise à analyser les significations produites par les professionnels de la santé en relation avec les soins de santé dans trois communautés Quilombola dans la vallée do Guaporé, dans l'État de Rondônia, au Brésil. La méthodologie utilisée a été l'approche qualitative. La construction du corpus a été réalisée par des entretiens semi-structurés avec six professionnels de santé et la technique d'analyse a été l'analyse du discours influencée par la perspective du constructivisme social. Les significations produites par les professionnels, soulignées à travers leurs discours, ont permis d'identifier quatre répertoires interprétatifs: 1) construction sociale du résidu quilombola à partir de la différence: de la cordialité, du retard et du désintérêt; 2) problèmes de santé mentale dans la communauté; 3) des aspects sociaux, culturels et symboliques de la communauté en tant que pratiques de soins de santé mentale; et 4) des obstacles à l'attention: distances théoriques-pratiques et l'(i) mobilité. Les réflexions sur les discours désormais présentées mettent en évidence la nécessité d'une formation continuée des professionnels de santé de la population noire afin qu'il y ait une réflexion critique sur la réalité et les conditions sociales inhérentes à la santé de cette population.

Mots-clés : professionnel de la santé ; communauté quilombola ; santé publique.

O sistema público de saúde do Brasil, denominado Sistema Único de Saúde (SUS), surgiu a partir de um histórico de lutas do movimento sanitário brasileiro (Carvalho, 2013) com a finalidade de democratizar o atendimento de saúde. Criado mediante a Constituição Federal (1988) como uma nova formulação política e organizacional para o reordenamento dos serviços e ações de saúde, o SUS foi consolidado pela Lei n. 8.080 (1990), que sedimenta as suas orientações constitucionais, e pela Lei n. 8.142 (1990). Esta última trata do envolvimento da comunidade na condução das questões da saúde, criando as conferências e os conselhos de saúde nas esferas municipal, estadual e federal do governo como instâncias colegiadas orientadoras e deliberativas, respectivamente.

Esse sistema tem como princípios constitucionais: a universalidade, ou seja, o acesso público e gratuito às ações e serviços de saúde a todo e qualquer cidadão garantido pelo governo municipal, estadual e federal; a integralidade das ações de saúde, cuidando do indivíduo como um todo, e não como um amontoado de partes, e a equidade, que garante igualdade a todos os cidadãos, como o dever de atender ao direito de cada um, respeitando suas diferenças (Brasil, 2004).

Reconhecido como sistema público de saúde, o SUS tem como função, portanto, exercer ações públicas, tanto no âmbito individual quanto no coletivo, com ações de promoção, proteção e recuperação da saúde em todos os campos (Carvalho, 2013). Em decorrência desses princípios e diretrizes, o SUS ganhou destaque e proeminência tanto em saúde pública quanto privada, contudo esse sistema apresenta limitações, como a falha na oferta de um serviço de saúde de qualidade em regiões isoladas.

Estudos realizados no Brasil revelam que os indicadores de saúde, quando cruzados com as características socioeconômicas e seus determinantes sociais, apontam para o diferencial de acesso, de tratamento e de resultados que populações e grupos específicos enfrentam na relação com o sistema de saúde (Brasil, 2016, 2017; Chehuen et al. 2015; Freitas, Caballero, Marques, Hernández, \& Antunes, 2011; Gomes, Reis, Guimarães, \& Cherchiglia, 2013). Isso mostra que a construção de um SUS 
equitativo no acesso e pautado na integralidade da saúde requer o reconhecimento das demandas de grupos específicos para atuar na redução do impacto dos determinantes sociais da saúde aos quais estão submetidos. Assim, variáveis como raça/cor e etnia são relevantes para atender ao princípio da equidade (Brasil, 2017). Na tentativa de solucionar essa lacuna, em 2009, o Ministério da Saúde, em conformidade com o ParticipaSUS, instituiu a Política Nacional de Saúde Integral da População Negra (PNSIPN), a qual teve por objetivo promover a equidade e a saúde integral da população negra, reduzir as desigualdades étnico-raciais e combater o racismo e a discriminação nas instituições e nos serviços do SUS como determinantes sociais das condições de saúde (Brasil, 2017).

Almeida (2019) diferencia conceitualmente os termos racismo, preconceito e discriminação. O racismo seria uma forma sistemática de discriminação que tem a raça como fundamento, a qual se materializa em ações, conscientes ou inconscientes, que culminam em vantagens ou desvantagens, dependendo do grupo racial ao qual pertencem. Já o preconceito racial é o juízo baseado em estereótipos relacionados a indivíduos que pertencem a um determinado grupo racial, que pode ou não resultar em práticas discriminatórias. Já a discriminação racial é a atribuição de tratamento diferenciado a grupos raciais identificados. O autor destaca, ainda, que o racismo pode se apresentar em três concepções: individualista (relação entre racismo e subjetividade), institucional (relação entre racismo e Estado) e estrutural (relação entre racismo e economia).

A PNSIPN busca estratégias para o enfrentamento das desigualdades étnico-raciais no contexto do SUS. Nessa perspectiva, a PNSIPN tem por finalidade visar a promoção, prevenção, atenção, tratamento e recuperação de doenças, vistas em detrimento transitivo e intransitivo, abrangendo com maior índice de prevalência populacional (Chehuen et al., 2015), incluindo as comunidades quilombolas, as quais foram tomadas como objeto de estudo nesta pesquisa.

De acordo com o Decreto n. 4.887 (2003), quilombolas são grupos étnico-raciais, segundo critérios de autoatribuição, com trajetória histórica própria, dotados de relações territoriais específicas, com presunção de ancestralidade negra relacionada com a resistência à opressão histórica sofrida. Por comunidades quilombolas se compreendem os grupos sociais e tradicionais negros que resistiram ao regime escravista, os quais formaram territórios independentes constituídos por meio da sua cultura, trabalho, resistência e oposição ao regime de trabalho escravo (Brasil, 2016).

Estima-se que existam no Brasil mais de quatro mil comunidades. A maioria está localizada no meio rural e/ou isolada na floresta, vivendo em situação de vulnerabilidade social (Melo \& Silva, 2015). Em razão do processo histórico de escravização, ao qual foi submetida essa população, foram acarretadas a ela diversas diferenças sociais e de saúde, menor acesso a bens e serviços, o que pode ocasionar, também, maior dificuldade de utilização de serviços de saúde (Gomes et al., 2013). Tal condição foi revelada pelo Plano Nacional de Saúde, 2012-2015, documento basilar de orientação das políticas e ações do SUS, como necessidade de ampliação do acesso aos serviços de saúde e o enfrentamento da iniquidade e da vulnerabilidade relacionadas à população quilombola (Brasil, 2016).

Diante dessa problemática, várias ações têm sido viabilizadas pelo Ministério da Saúde com o objetivo de promover melhor assistência à saúde da população quilombola. Uma dessas políticas é a PNSIPN, que traz entre seus objetivos a garantia e a ampliação do acesso da população negra do campo e da floresta, em particular as populações quilombolas, às ações e aos serviços de saúde, bem como o estabelecimento de metas específicas para a melhoria dos indicadores de saúde dessas populações (Brasil, 2017). Além disso, o art. $4^{\circ}$ da Resolução n. ${ }^{\circ}$ 16, de 30 de março de 2017, que reza sobre a elaboração de projetos e ações de saúde voltados à população negra, propõe como estratégia a qualificação e o fortalecimento do acesso das comunidades quilombolas e tradicionais aos serviços de saúde da atenção básica, conforme a Política Nacional de Atenção Básica (PNAB) (Brasil, 2017).

Embora essas políticas tenham contribuído para a redução das desigualdades no Brasil, elas parecem ainda não ter sido suficientes para assegurar, na prática, uma assistência em saúde equitativa às comunidades de remanescentes de quilombos, que se encontra profundamente agravada (Melo \& Silva, 2015). Estudos têm apontado que são vários os condicionantes sociais associados aos problemas de saúde nas comunidades quilombolas. Fatores como desemprego (Santos, 2018; Santos \& Silva, 2014), baixa escolaridade (Chehuen et al., 2015; Melo \& Silva, 2015), criminalidade, intolerância religiosa (Santos, 2018), péssimas condições de moradia, falta de lazer e dificuldade de acesso a bens e serviços (Cardoso, Melo, \& Freitas, 2018; Teixeira \& Xavier, 2018) têm sido fortemente apontados como potencializadores dos problemas de saúde nessas comunidades. Como comorbidades, esses condicionantes apresentam forte relação com a prevalência de doenças crônicas (Melo \& Silva, 2015) e problemas de saúde mental, como depressão e consumo de álcool e outras drogas (Barroso, Melo, \& Guimarães, 2014; Cardoso, Melo, \& Cesar, 2015; Santos et al., 2016; Silva \& Menezes, 2016; Vieira \& Monteiro, 2013).

Além desses condicionantes, as pesquisas têm apontado para a precariedade dos serviços de saúde oferecidos, como escassez de profissionais, número reduzido de unidades que prestam atendimentos nas comunidades, competindo aos agentes de saúde o acompanhamento das famílias quilombolas (Vieira \& Monteiro, 2013). Acrescenta-se que, em razão do grau de isolamento em que se encontra a maioria das comunidades, a rotatividade de profissionais é acentuada, comprometendo o tratamento contínuo (Santos \& Silva, 2014). Assim como em outras comunidades rurais, esses fatores contribuem para um modelo de assistência em saúde e à saúde mental marcado pela tecnificação, objetificação, biologicismo, mecanicismo, hospitalocentrismo, curativismo e especialismo (Costa \& Dimenstein, 2017). 
No que se refere às comunidades quilombolas do Vale do Guaporé, no estado de Rondônia, suas condições não são muito diferentes em relação aos aspectos socioeconômico-ambientais de outras comunidades da região Norte do País (Melo \& Silva, 2015; Oliveira, Rodrigues, Corrêia, Tavares, \& Monteiro, 2011), marcadas por acentuado grau de isolamento e exclusão social. Com relação às condições e ao acesso à assistência em saúde das comunidades remanescentes de quilombos do Vale do Guaporé, não foram encontradas pesquisas específicas sobre a temática. No entanto os estudos que trazem essa problemática como viés de suas discussões revelam que as condições precárias de saúde afetam a vida daqueles que vivem nessas comunidades (Farias, 2011; Teixeira \& Xavier, 2018). Tais condições vêm sendo, muitas vezes, responsáveis pelo êxodo de muitos familiares que, diante da complexidade da doença, mudam da comunidade para assegurar melhor tratamento em áreas urbanas (Teixeira \& Xavier, 2018).

Xavier (2012), na pesquisa sobre acesso das mulheres quilombolas à atenção básica na região Sul do Brasil, relata uma série de situações nas quais as mulheres vivenciam o racismo em suas diferentes perspectivas. Desde o racismo institucional relacionado à dificuldade de acesso aos serviços por viverem em áreas não regulamentadas, até a afirmação de profissionais de que não é necessário incluir dados sobre raça e etnia no prontuário, pois não consideram importantes.

Tendo em vista as questões problematizadoras expostas, este texto apoia-se numa perspectiva construcionista, a qual compreende que a construção da realidade ocorre em meio aos coletivos, por intermédio da cultura e dos modos que as pessoas elegem para vivenciar uma dada realidade (Cadoná \& Scarparo, 2015). A partir de uma postura crítica e reflexiva, o construcionismo social privilegia as interações sociais e considera a linguagem uma forma de ação social na construção ativa do mundo (Gergen, 1997; Rasera \& Japur, 2007). Além disso, a compreensão do outro como sociedade e o compromisso político com as questões da atualidade, são aspectos relacionais presentes na discussão dentro de uma inteligibilidade construcionista social (Rasera, Guanaes-Lorenzi, \& Corradi-Webster, 2016).

Desse modo, conhecer como ocorre a construção social das práticas de serviços de saúde oferecidos nas comunidades quilombolas do Vale do Guaporé se torna de grande relevância no processo de desenvolvimento de ações efetivas que dialogam com os princípios do SUS. Sendo assim, este estudo teve como ponto de partida as seguintes questões norteadoras: quais são os sentidos produzidos sobre as práticas em saúde/saúde mental exercidas pelos profissionais de saúde pública com a população quilombola do Vale do Guaporé, RO? Como essas práticas podem revelar a desigualdade, o preconceito e a exclusão sofridos pela comunidade através do viés do sistema de saúde pública?

Refletir sobre os sentidos que essas práticas produzem no cotidiano de trabalho desses profissionais é de fundamental importância para a melhoria da qualidade do serviço de saúde pública oferecido nessas comunidades. Desse modo, partindo dessas considerações preliminares, este artigo tem por objetivo analisar os sentidos produzidos por profissionais de saúde em relação à atenção à saúde em três comunidades quilombolas do Vale do Guaporé, no estado de Rondônia.

\section{Método}

A pesquisa realizada fundamenta-se em uma abordagem qualitativa, orientada pela perspectiva construcionista social (Gergen, 1997). A abordagem metodológica ora assumida compreende os sentidos que as pessoas constroem sobre si mesmas e sobre o mundo como um empreendimento coletivo e interativo, por meio do qual as pessoas, na dinâmica das relações sociais historicamente datadas e culturalmente localizadas, constroem os termos a partir dos quais compreendem e lidam com os fenômenos a sua volta (Spink \& Medrado, 2004).

Este estudo foi elaborado na busca de descrever os serviços de saúde/saúde mental, vistos como uma prática social dentro de um contexto histórico e cultural, cujos sentidos são construídos pelas interações entre os profissionais de saúde e a comunidade quilombola por meio das suas práticas discursivas no cotidiano (Spink \& Medrado, 2004). De acordo com Iñiguez (2004), são inúmeros os procedimentos analíticos, e estes podem ser realizados em diferentes níveis dentro da teoria de análise do discurso. Neste estudo, enquanto procedimento analítico, optou-se pela utilização dos repertórios interpretativos, conceito introduzido por Potter e Wetherell (1987), os quais são marcados por termos, metáforas, sinais, figuras de linguagem e imagens que são utilizadas na conversação. Ainda de acordo com os autores, os repertórios interpretativos estão locados num nível individual, mas são compartilhados e estão disponíveis como um recurso social. As pessoas os utilizam para justificar alguma versão particular de um evento, para validar ou questionar os próprios comportamentos e para manter sua credibilidade na interação (Potter \& Wetherell, 1987).

Foram convidados a colaborar com este estudo 10 profissionais, integrantes de duas equipes de saúde de dois municípios do estado de Rondônia, os quais atendem três comunidades quilombolas do Vale do Guaporé. Destes, participaram seis. As equipes de saúde que atendem as comunidades quilombolas do Vale do Guaporé não são formadas especificamente para atender essa população. Assim, ela é formada por profissionais que atuam na saúde básica de cada município e fazem atendimento às comunidades de acordo com o calendário da secretaria de saúde de cada município. A rotatividade de profissionais é constante durante o ano e nem sempre as comunidades recebem atendimento das mesmas especialidades em saúde com a 
mesma frequência. Foram considerados os seguintes critérios para inclusão no estudo: 1) profissionais que faziam parte da equipe de saúde que atendia pelo menos uma comunidade quilombola em loco; e 2) disponibilidade de horário.

Tomando como base o enfoque teórico construcionista na perspectiva da Psicologia Discursiva, que tem como premissa o desenvolvimento de investigação sobre os aspectos construtivos da linguagem na interação social como forma de produção de sentidos (Potter \& Wetherell, 1987), foi elaborado um roteiro de entrevistas semiestruturadas com questões que buscavam explorar os sentidos produzidos sobre o cuidado em saúde mental/doença mental pelos profissionais de saúde.

As questões foram divididas em quatro blocos temáticos: atuação profissional, conhecimento sobre saúde/doença mental, identificação de doença mental na comunidade e políticas públicas em saúde mental. Além da entrevista, foi utilizado um formulário cpara coletar dados demográficos: nome, idade, formação, tempo de atuação nas comunidades e capacitação em saúde mental.

O primeiro contato para a realização da pesquisa foi com a direção de cada unidade, ocasião em que foi solicitada a autorização do responsável para a realização do estudo. Com o nome de cada possível colaborador e o horário de atividades exercidas por ele na unidade, foi realizado o contato com cada um, no qual foram apresentados os objetivos da pesquisa e feito o convite à participação. Nas datas e horários acordados, realizaram-se as entrevistas individuais com cada profissional em sua respectiva sala de atendimento, após o encerramento da sua jornada diária de trabalho. As entrevistas foram audiogravadas, perfazendo um total de seis horas de gravação. Antes de serem iniciadas as entrevistas, os participantes leram e assinaram o Termo de Consentimento Livre e Esclarecido (TCLE).

O caminho escolhido para analisar o corpus se baseou na proposta de análise do discurso influenciada pelo construcionismo social (Potter \& Wetherell, 1987; Rasera \& Japur, 2007; Spink \& Medrado, 2004). A partir dessa proposta, foi realizada a transcrição, a leitura flutuante e atenta das entrevistas, a seleção do tópico grupal, e a identificação dos repertórios interpretativos (Potter \& Wetherell, 1987).

O projeto foi submetido à avaliação e aprovado pelo Comitê de Ética em Pesquisa da Pontifícia Universidade Católica do Rio Grande do Sul (PUCRS), sob o Parecer n..$^{\circ}$ 2.410.908 e CAAE . $^{\circ}$ 79939417.7.0000.5336. Ressalta-se que, para preservar o sigilo dos participantes, os nomes foram substituídos pela palavra Entrevistado seguida de um número referente à ordem em que foi realizada a entrevista.

\section{Resultados e Discussão}

A partir dos discursos dos profissionais foram construídos os seguintes repertórios interpretativos: 1) a construção social do remanescente quilombola a partir da diferença: cordialidade, atraso e desinteresse; 2) problemas de saúde mental na comunidade; 3) aspectos sociais, culturais e simbólicos da comunidade como práticas de cuidado em saúde mental; e 4) entraves na atenção: distanciamentos teórico-práticos e (i)mobilidades. Essas construções interpretativas foram fundamentais para o entendimento e a compreensão das relações que envolviam a construção dos sentidos sobre as práticas em saúde mental desempenhadas pelos profissionais nas comunidades quilombolas do Vale do Guaporé.

\section{A Construção Social do Remanescente Quilombola a partir da Diferença: Cordialidade, Atraso e Desinteresse}

Nesse repertório buscou-se, através das práticas discursivas dos entrevistados, compreender os sentidos sobre a construção identitária do quilombola do Vale do Guaporé. Os discursos mostram que a relação do profissional com a comunidade possui um duplo caráter de linguagem, construída historicamente, mas também construtora de realidade (Gergen, 1997). Se, por um lado, essa experiência amplia a produção de saberes sobre essa população, por outro lado, essa relação também contribui para a construção social desses sujeitos.

As falas dos profissionais sobre os aspectos gerais dos membros das comunidades apontam para diferentes definições e produções de sentido em relação à população. A contextualização, a partir da questão como você define a população quilombola?, produziu concepções distintas entre os entrevistados, ganhando conotações de pessoas afetivas, gratas, acolhedoras e humildes, como mostram os trechos a seguir.

[...] eles possuem um vínculo afetivo muito grande e diferente da tradição e da cultura daqui da cidade (Entrevistado 1).

As pessoas lá (quilombolas), a maioria são bem gratas. Quando a gente vai, tratam a gente bem, ficam felizes porque a gente ajuda eles (Entrevistado 3).

A população quilombola é muito acolhedora e recepciona bem as pessoas que vão até lá ajudá-las, e é uma comunidade bem humilde, onde eles não têm certos costumes como se tem na cidade. Então eles são bem receptivos, diferenciando de alguns daqui da cidade. Eles [os quilombolas] são mais abertos ao tratamento que a gente faz a eles, tratamentos preventivos (Entrevistado 6). 
A análise discursiva das falas anteriores mostra que a construção social identitária dessas pessoas é marcada pela diferença, ou seja, é afirmada por meio da negação. Assim, o profissional reconhece-o pelo que ele não é, como mostram os trechos: "é diferente da tradição e da cultura de São Francisco"; "eles não têm certos costumes como se tem na cidade"; "eles são bem receptivos, diferenciando de alguns daqui da cidade". De acordo com Silva (2014), a identidade marcada pela diferença ocorre tanto por meio de sistemas simbólicos de representação quanto por meio de exclusão social. Já as características apontadas, como pessoas "acolhedores", "afetivas" e "gratas", podem ser compreendidas como uma forma de comportamento "adestrado" do remanescente, visto como positivo para esses profissionais, considerando que não há contestação ao que lhes é oferecido. Em outros momentos da entrevista fica clara essa interpretação quando um entrevistado afirma que "[...] a maioria deles (quilombolas) entra mudo e sai calado do atendimento. Pega a medicação e vai embora sem falar uma palavra" (Entrevistado 6), ou seja, aceita o que lhe é oferecido sem contestação.

Outro fato que chamou a atenção foi o desconhecimento da história dos remanescentes quilombolas ao serem associados aos negros do período da escravatura brasileira. "Nas minhas palavras quilombolas são pessoas bem antigas, que são escravos, porque quilombo são escravos, né, a palavra [...] de quilombos, né, por ser a história deles" (Entrevistado 4). Por outro lado, essa fala remete à análise anterior, uma vez que a palavra escravo se associa à servidão, à submissão, entre outras. Nesse sentido, Gergen e Gergen (2010) destacam que cada maneira de construir o mundo sustenta certas tradições carregadas de valores particulares, ao passo que, simultaneamente, ignora tudo que estiver fora delas. Assim, não existem descrições isentas de valores.

Já na construção a seguir atribui-se o sentido de "povo atrasado" ao se definir a população quilombola: "[...] eles estão anosluz atrasados em relação à sociedade" (Entrevistado 5). Observa-se que esse entrevistado usa como referência a sociedade "civilizada" para justificar a "inferioridade" dos remanescentes. Esses estereótipos e generalizações apontam para uma relação entre profissional e comunidade hierarquizada, perpetuando uma visão distorcida desta como inferior. Assim como aponta Almeida (2019), essa fala materializa o racismo, no qual se estabelece uma hierarquia de poder entre um grupo e outro determinado pela questão racial.

Durante as conversas, pode-se observar que o apoio às comunidades é percebido por alguns dos profissionais como privilégio, ou seja, algo que está além do seu merecimento, como mostra a fala a seguir: "temos uma casa aqui exclusiva pra eles, onde tem televisão, cama, fogão e, ainda, tem comida. Quando eles vêm pra cá, eles ficam nessa casa e até alimentação tem pra eles" (Entrevistado 4). Outra construção a ser destacada é a de um povo necessitado, dependente do poder público:

[...] eles, [quilombolas] têm alguns que se interessam, [que] estão fazendo faculdade de Pedagogia [...], que se interessam em estudar, fazer um curso de aperfeiçoamento, alguma coisa. Como a gente vê aqueles que não têm interesse algum. [...] eles querem muito que a ação social dê, e a gente vê que a maioria não dá algo em troca, de se qualificar, de fazer alguma coisa. (Entrevistado 2) [...] eles reclamam, eu acho, que à toa, sem necessidade nenhuma. (Entrevistado 4)

Vejo eles [os quilombolas] como os "beradeiros" [pessoas que moram às margens do rio], preguiçosos. Aqueles ali só sabem beber e pescar, são muito preguiçosos (risos). (Diário de campo)

Os trechos recortados das entrevistas e do diário de campo materializam uma série de estereótipos relacionados às pessoas negras, que geram preconceito racial (Almeida, 2019). No momento em que os profissionais qualificam os integrantes das comunidades como "preguiçosos", "beradeiros", "que não têm interesse nenhum", "que têm interesse só na ação social", se produz uma série de generalizações, verdades e estereótipos, que têm grande potencial para a produção de práticas discriminatórias no contexto de atenção à saúde. Assim, essas afirmações preconceituosas, que emergem nessas falas, podem se refletir na relação entre profissional e comunidade e gerar práticas discriminatórias.

Santos (2018) ressalta que existe um imaginário social de que o negro é sujo, preguiçoso e indesejável, e que esses estereótipos são um dos condicionantes de saúde, o que, na atualidade, é destruidor de subjetividades. Nesse sentido, assim como destaca Almeida (2019), operam tanto o racismo individualista (relação entre racismo e subjetividade) quanto o institucional (relação entre racismo e Estado), já que, nesse contexto, o Estado opera através dos profissionais da saúde.

Outro elemento importante é a ideia de que eles estão recebendo demasiado do Estado, uma ideia que se materializa nas frases: "a gente vê que a maioria não dá algo em troca, de se qualificar, de fazer alguma coisa" e "eles reclamam, eu acho, que à toa, sem necessidade nenhuma". Essas falas levam à análise do sofrimento ético-político dessa população como formas sutis de espoliação humana por trás da aparência da integração social, a partir do entendimento da exclusão e da inclusão como as duas faces do mesmo problema: a desigualdade social e a exploração (Sawaia, 2014).

A análise em contexto explicita como esses estereótipos operam em processos de exclusão que pode afetar a saúde mental dessa população. Para Lages, Tavares, Santos, Carvalho, \& Maciel (2014), os preconceitos e o desmerecimento das identidades culturais afetam o sujeito psíquico, provocando, entre outros sintomas, a depressão, a desmotivação e a baixa autoestima.

É possível inferir que os discursos de componentes negativos que emergiram nas entrevistas ora apresentadas podem estar relacionados a construções sociais fundadas no desconhecimento do processo de formação sócio-histórico e cultural dessas 
comunidades e no despreparo teórico e prático das equipes de saúde. De acordo com Oliveira, Gellacic, Zerbinatti, Souza, e Aragão (2012), em uma revisão de literatura sobre preconceito no SUS, concluíram que o preconceito no campo dos serviços de saúde é evidenciado, sobretudo, pelo déficit no preparo e conhecimento profissional acerca das políticas de saúde que integram o SUS. Nesse sentido, assim como destacam Guanaes e Japur (2008), os diálogos desenvolvidos entre os participantes do grupo são também atravessados pelas inúmeras vozes sociais que orientam suas descrições de mundo, de problemas e de si.

\section{Problemas de Saúde Mental na Comunidade}

Condicionantes sociais como discriminação, violência institucional cotidiana, exclusão social, preconceito, baixa autoestima, pobreza, abuso do álcool e de drogas são fatores que podem "levar a população negra ao sofrimento psíquico, em formas e intensidades diversas" (Brasil, 2016). Nesse repertório, focalizou-se o contexto de produção de sentidos sobre os problemas de saúde mental presentes nas comunidades percebidos pelos profissionais durante suas práticas cotidianas.

Com relação à saúde mental dos membros das comunidades, os sintomas depressivos foram os principais problemas apontados pelos profissionais entrevistados. "[...] lá (comunidade Jesus) já teve umas três pessoas que tiveram depressão" (Entrevistado 5). Na fala a seguir, a colaboradora aponta para o crescimento dos diagnósticos: “[...] o número de pessoas com depressão vem aumentando nas comunidades. Atendi já alguns casos de depressão" (Entrevistado 6).

Esses resultados corroboram outros estudos nacionais que têm apontado para a presença de sintomas depressivos nas comunidades quilombolas (Barroso et al., 2014; Oliveira, Pereira, Guimarães, \& Caldeira, 2015). Além da depressão, um caso de esquizofrenia foi relatado por um profissional “[...] esquizofrenia, teve um caso em [comunidade] Santo Antônio [...]" (Entrevistado 6).

De acordo com Oliveira et al. (2015), as comunidades quilombolas passam por várias limitações sociais, que podem contribuir para o aumento da depressão, pois o indivíduo que se sente deprimido, muitas vezes sente-se excluído socialmente. Em outra fala, o profissional remete aos conteúdos inconscientes para explicar a manifestação dos sintomas depressivos: "[...] eles trazem muito material inconsciente, como lembranças do seu passado. Eles vêm carregados de muita emoção" (Entrevistada 1). Por outro lado, essas emoções parecem refletir as desigualdades e a exclusão social, que provocam uma série de sofrimentos psíquicos nesses sujeitos (Lages et al., 2014), que acabam, por muitas vezes, despotencializando-os para ações de resistência e luta no sentido de superar as situações de subalternidade (Sawaia, 2014).

A relação do adoecimento psíquico com a perda de um familiar também foi observada por um entrevistado: "geralmente, os casos de depressão eram em pessoas que perderam alguém, um ente querido. Todos os casos que eu atendi foram porque houve a morte de alguém. A depressão não estava associada há outros fatores" (Entrevista 1). Nesse caso, o adoecimento pode ser explicado pela incapacidade de lidar com a angústia após o rompimento de um vínculo afetivo entre os membros: "eles são muito apegados uns aos outros. Eles estão todos sempre juntos" (Entrevistado 1).

Esses dados tornam-se relevantes para a discussão, uma vez que favorece novas formas de compreensão e produção de sentidos da realidade desses profissionais no campo da saúde mental no contexto sócio-histórico-cultural em que se inserem essas comunidades. Assim, a construção dialógica entre o saber científico e os saberes populares presentes nas comunidades podem direcionar a um fazer comprometido e articulado com novas formas compartilhadas de se pensar a saúde mental nesses espaços, que apontam para valorização de diferentes saberes, com foco no processo relacional e no fazer conjunto (Camargo-Borges, 2007).

A respeito do consumo de bebidas alcoólicas, a análise da produção discursiva evidencia um discurso hegemônico entre os profissionais, em que o consumo de álcool nas comunidades é compreendido como parte da cultura ou tradição: "[...] o consumo de álcool faz parte da própria cultura deles. Não como um vício [...]." (Entrevistado 6) e “[...] o alcoolismo deles vem junto com a tradição deles." (Entrevistado 2). Essas informações alinham-se a outros estudos, os quais encontraram em seus resultados consumo excessivo de bebidas alcoólicas em comunidades quilombolas (Cardoso et al., 2015; Silva \& Menezes, 2016). O consumo contínuo de bebidas alcoólicas também foi associado às festividades que acontecem nas comunidades, como as festas religiosas e as comemorações de aniversários, as quais são sempre prolongadas, como mostram as falas a seguir:

[...] todas as comunidades ingerem muito álcool. Todas as festividades têm a questão do álcool. Geralmente, quando eles ingerem bebida, são dois, três dias seguidos. (Entrevistado 3)

[...] assim, não é só aquele dia. Por exemplo: se vai comemorar o aniversário de um membro, aí começa a beber hoje, aí amanhã continua, depois de amanhã continua. Então, assim, é um índice muito grande, também, de alcoolismo. (Entrevistado 1)

O uso excessivo de bebida alcoólica apontado nas falas anteriores repercute de forma negativa entre os moradores: "às vezes, há entre eles essas desavenças (conflitos). Há uns três meses teve uma briga muito grande que um esfaqueou o outro" (Entrevistado 4) e “[...] a gente também já fez algumas intervenções, palestras" (Entrevistado 5). Embora os profissionais reconheçam os efeitos negativos do consumo excessivo de bebidas alcoólicas nas comunidades, e até mencionem a realização 
de intervenções, não foram apresentados os resultados dessas atividades.

Os entrevistados ainda destacam as influências da expansão do agronegócio na região como meio de inserção de bebidas nas comunidades: "acredito que (o alcoolismo) seja presente em qualquer região onde tenha fazenda. Por exemplo, os peões de fazenda são muito adeptos a bebidas alcoólicas" (Entrevistado 6). E ainda sugerem que o consumo de bebidas está relacionado à religião: "[...] a gente também pensa assim: bom, comunidade africana.... eles são adeptos ao álcool por causa dos rituais que eles faziam" (Entrevistado 6). Observa-se, nesta última fala, que o profissional se utiliza de um discurso preconceituoso ao sugerir que o uso de bebidas alcoólicas durante algumas práticas religiosas de matrizes africanas influencia o consumo excessivo de álcool entre todos os membros das comunidades.

\section{Aspectos Sociais, Culturais e Simbólicos como Práticas de Cuidado em Saúde Mental}

Os saberes das comunidades remanescentes de quilombolas, em suas várias manifestações, compreendem um conjunto de práticas cotidianas, agrícolas e ecológicas, ligadas à biodiversidade e às expressões artísticas e religiosas, preservando uma herança cultural e material de valor inestimável (Silva \& Lisboa, 2012). Nesse repertório, buscou-se identificar como os profissionais de saúde percebem os saberes tradicionais e culturais presentes no cotidiano das comunidades quilombolas e como esses recursos são utilizados no enfrentamento de possíveis manifestações de sintomas de transtorno mental. Os trechos a seguir mostram que as práticas religiosas representadas nas figuras da benzedeira e do curandeiro e o uso de ervas e plantas são evidenciados como elementos que mantêm a relação das comunidades com a tradição e o espaço natural.

Quanto à percepção do uso de práticas religiosas presentes nas comunidades como forma de tratamento, os entrevistados foram unânimes em suas respostas: "lá existem alguns curandeiros, sim." (Entrevistado 3). Essa fala mostra como a religião demarca os valores culturais e religiosos dessas comunidades.

Eles acreditam, também, quando alguém está ruim (enfermo), se alguém falar para eles que foi trabalho, foi macumba, eles acreditam, e não tem nada que faça mudar essa ideia da cabeça deles. Aí eles vão e procuram benzedeiras, procuram mãe de santo para tirar aquele trabalho que foi feito. (Entrevistado 5)

[...] eles trazem com eles também a tradição negra, as religiosidades de matrizes africanas. Eles acreditam em trabalho feito, e não conseguem tirar isso deles. [...] acreditam fortemente em curandeirismo... (Entrevistado 6)

A compreensão dos quilombolas em relação ao processo saúde-doença e à religiosidade não parece ser integrada às práticas de saúde dos profissionais. Ao contrário, a ideia parece ser "tirar isto deles ou da cabeça deles" (Entrevistados 5 e 6). Tal compreensão por parte da equipe não busca enfatizar as representações desse processo, o qual parece explicitar o substrato social das construções que este grupo faz da doença e da saúde (Spink, 2013).

Esses discursos reafirmam a força da tradição mantida por essa população, mesmo após um longo período de influências de outras culturas. Os benzedores e "pais de santo" eram figuras respeitadas pelos escravos e temidas pelos senhores, sendo a eles atribuídos poderes místicos e desconhecidos (Souza, 2012). Além das práticas religiosas de matriz africana, as falas a seguir apontam para a influência exercida pela religião católica sobre a comunidade:

[...] eles tiveram influência de outra religião (catolicismo), [...] porque a igreja católica sempre manteve a questão de ajuda, construção, essas coisas. (Entrevistado 5)

Eles fazem todos os anos a Festa do Divino Espírito Santo, a festa da Nossa Senhora da Conceição. [...] Eles fazem uso de terço, orações, cantam o pai-nosso. (Entrevistado 3)

Eles fazem a festa de São João, as festas juninas, fogueira, banho de santo, toca o sino da igreja, todas essas tradições católicas eles fazem. (Entrevistado 1)

Eles são muito religiosos, muito apegados aos santos deles. Nossa, é uma coisa linda essa tradição deles. (Entrevistado 2)

Diante dessas falas, percebe-se que a construção da religiosidade dos quilombolas em questão parece ser em um misto de religião católica e dos cultos de origem africana. Tal fato pode ser compreendido através do sincretismo religioso de matriz africana, com significado fornecido pelos santos católicos e arquétipos nativos, como argumenta Souza (2012). No entanto nem sempre o uso das práticas religiosas nas comunidades parece ser percebido como elemento positivo pelos profissionais, pois, ao serem indagados sobre em que medida as práticas religiosas contribuem no tratamento e para amenizar o sofrimento mental nas comunidades, deram a seguinte resposta:

Eles trazem a questão da macumba, que se alguém está ruim (enfermo), 'ah, foi macumba que jogou em mim'. [...] uma pessoa da comunidade botou na cabeça que (a enfermidade dela) era macumba e já sabia até o nome da pessoa que tinha colocado a 
macumba. Então isso daí atrapalhou muito. (Entrevistado 6)

O trecho apresentado mostra que os saberes advindos da cultura religiosa da comunidade são vistos pelo profissional como algo que dificulta o tratamento. No entanto, tal concepção parece desconsiderar que esses valores preservados são civilizatórios e podem ajudar no conhecimento e no entendimento de outras formas e olhares sobre como cada comunidade produz sentidos a respeito do mundo ao seu redor, e como dialogam com as relações que constroem entre si e o ambiente que a cerca e, consequentemente, suas práticas cotidianas com a saúde (Freitas et al., 2011). Nesse sentido, a desconstrução dessa visão envolve, entre outras coisas, o desenvolvimento de processos de informação, comunicação e educação que desconstruam estigmas e preconceitos, fortaleçam uma identidade negra positiva e contribuam para a redução das vulnerabilidades (Brasil, 2017).

Ainda nesse repertório, buscou-se analisar a influência da cultura indígena e ribeirinha na vida das pessoas das comunidades quilombolas do Vale do Guaporé. Além da religiosidade, o uso de ervas medicinais retiradas da floresta foi percebido pelos profissionais de saúde como forte aliada dos quilombolas do Vale do Guaporé no enfrentamento das doenças. Nesse sentido, os saberes tradicionais e o respeito às noções de saúde que essas comunidades possuem são necessários, pois, além de possuírem sua própria eficácia, eles rompem com os paradigmas da medicina ocidental (Freitas et al., 2011), que rege o cuidado em saúde, sobretudo em saúde mental.

Em algumas falas, apresentadas a seguir, observa-se uma junção das duas práticas, comuns nas aldeias indígenas, o que é desenvolvido pelo pajé, que, além de curandeiro espiritual da tribo, utiliza ervas e plantas medicinais no tratamento:

Eles acreditam [em cura] através de chás medicinais guiados por um guia espiritual [...]. Então, a gente também não desrespeita a crença. A gente fala tudo bem, só que, assim, acho muito importante você fazer isso [o tratamento com os chás], porque é uma cultura que vocês devem manter, no entanto é muito importante que vocês façam o tratamento médico. (Entrevistado 6)

A fala anterior mostra que explorar ativamente as narrativas de recursos e potencialidades das comunidades é um posicionamento ético e político, que ilumina aspectos frequentemente pouco explorados em nossa sociedade e permite flexibilizar as metanarrativas, desnaturalizando-as (Guanaes-Lorenzi, 2014). Além disso, a troca de conhecimentos e experiências entre os profissionais e as comunidades faz parte do jogo relacional entre os atores envolvidos. Como afirmam Spink e Medrado (2004), "a pessoa, no jogo das relações sociais, está inserida num constante processo de negociação, desenvolvendo trocas simbólicas num espaço de intersubjetividade ou, mais precisamente, de interpessoalidade" (p. 55). Nesse sentido, pensar em saúde mental nessas comunidades requer o reconhecimento de que o cuidado em saúde mental não pode se resumir à abordagem biomédica e psiquiátrica, mas, sim, considerar os processos de saúde-doença desde uma perspectiva psicossocial.

De modo geral, a análise da construção discursiva dos profissionais mostra que as comunidades assistidas pela equipe, assim como outras comunidades quilombolas de outras regiões, utilizam de seus elementos culturais como meios de prevenção e cura. Valendo-se de recursos decorrentes da cultura na qual está inserida, essa população utiliza formas variadas de saberes advindos de práticas religiosas, bem como plantas e ervas medicinais como forma de tratamento. Como afirmam Silva, Dimenstein, e Leite (2013), as práticas de cuidado advindas dos saberes populares, por serem as primeiras iniciativas tomadas por essas pessoas no enfretamento ao adoecimento, devem ser potencializadas e consideradas como elemento primordial pelos profissionais que atuam nesses contextos.

Nessa direção, a democratização das práticas em saúde/saúde mental acontecerá, efetivamente, à medida que os sentidos de saúde-doença forem construídos não somente como resultado de uma descoberta científica em que somente um "saber", o científico, é privilegiado, mas, sobretudo, por meio de um imbricado processo de construção social, como uma pluralidade de vozes participando dessa construção (Camargo-Borges, 2014). Além disso, é preciso que novas estratégias sejam pensadas entre os profissionais e as comunidades, possibilitando diversas práticas de cuidado, em que cada ator envolvido dê um passo além de um único compromisso moral, da única crença verdadeira, aprendendo a conviver com a multiplicidade (Gergen \& Gergen, 2010).

\section{Entraves na Atenção: Distanciamentos Teórico-Práticos e (I)Mobilidades}

Nesse repertório buscou-se analisar as práticas discursivas que descreviam os desafios e dificuldades enfrentadas na prática de assistência à saúde às comunidades quilombolas. Por meio das falas, elegeram-se dois eixos de análise: a ausência de capacitação em saúde da população negra e as dificuldades de mobilidade para o desenvolvimento do atendimento in loco.

Para que a implementação de políticas de saúde da população negra seja eficiente, é necessário que vários atores que compõem esse campo, como gestores, movimentos sociais, conselheiros e, sobretudo, os profissionais do SUS, trabalhem em prol da melhoria das condições de saúde dessa população. Nessa direção é imprescindível que os profissionais sejam capazes de compreender as condições de vulnerabilidades das comunidades e de reconhecer os seus determinantes sociais em saúde. A PNSIPN traz, em uma de suas diretrizes, a inclusão dos temas racismo e saúde da população negra nos processos de 
formação e educação permanentes (Brasil, 2017). Quando interrogados sobre formação continuada, apenas um entrevistado afirmou ter realizado um curso de capacitação de longa duração.

[...] a última capacitação, acho que veio como um presente pra mim, que foi o curso de terapia comunitária. Foram três anos de curso aprendendo a fazer rodas de terapia comunitária, e assim me abriu um leque muito grande. [...] esse curso foi realizado pelo Estado. (Entrevistado 1)

Em outro momento da entrevista, chama atenção o fato de dois entrevistados associarem epilepsia a um transtorno mental. Ao serem interrogado sobre se eles tiveram alguma capacitação em saúde mental, responderam: "[...] já, sobre epilepsia" (Entrevistado 4) e "a gente teve uma palestra sobre epilepsia. Foi esse ano, há uns três meses" (Entrevistado 2).

A ausência de políticas públicas de formação dos profissionais repercute nas suas práticas, como no desenvolvimento de estratégias e ações na prática de ações afirmativas para alcance da igualdade em saúde, entre outras modalidades preventivas, nas comunidades: "[...] eu ainda não participei de nenhuma, até porque aqui no município não tem, eu teria que ir para fora" (Entrevistado 3). O entrevistado relaciona a falta de qualificação com a distância do município dos grandes centros, e afirma que as poucas informações sobre saúde mental foram obtidas por meio da internet e durante o curso de formação: "[...] eu estudei sobre saúde mental só um pouquinho durante minha graduação, numa disciplina de 40 horas" (Entrevistado 3).

Em outro momento, os profissionais não só reafirmam a ausência de capacitação, como manifestam sua necessidade: "[...] ainda não, nunca teve... Seria bom se tivesse" (Entrevistado 5), atribuindo ao poder público a responsabilidade: “[...] não, nenhuma. Seria importante uma capacitação, mas o município ainda não ofereceu" (Entrevistado 6). Essas falas registram a necessidade de melhor qualificação e o anseio desses profissionais pelo apoio de políticas voltadas à formação específica em saúde da população negra. A análise dos discursos produzidos evidencia uma hegemonia quanto ao fato de que os profissionais ainda não possuem nenhuma formação em saúde mental.

A ausência de capacitação desses profissionais em saúde mental implica o desenvolvimento de ações preventivas no enfrentamento dos inúmeros condicionantes sociais que marcam a saúde física e mental da população negra.

Além disso, o conhecimento dessa política configura-se como importante recurso no processo de superação do paradigma colonizador médico-psiquiátrico, para uma abordagem sócio-histórica da saúde mental capaz de atender às necessidades dessa população (Brasil, 2017). Para Santos (2018), essa política desenvolve uma concepção de saúde fomentada no reconhecimento dos saberes e práticas populares de saúde, sobretudo os saberes de matrizes africanas, e destaca a transversalidade como princípio organizativo das estratégias de saúde numa visão integral de sujeito, em conformidade com os princípios do SUS.

Outro tema analisado nesse repertório refere-se às dificuldades enfrentadas pela equipe de saúde em decorrência do isolamento das comunidades quilombolas do Vale do Guaporé.

Tem o fator distância, assim, os meios de locomoção, porque eles vêm uma vez por mês só. E aí fica difícil o atendimento justamente por causa disso, né, a distância. Mas se tivesse veículo, e se eles pudessem ficar na cidade e serem atendidos, eles ficariam. (Entrevistado 1)

É muito longe! Às vezes, a gente tem como ir, às vezes, não tem. [...] demora de cinco a seis horas para chegar lá. [...] a dificuldade é com o rio, é muito difícil pra você chegar lá. (Entrevistado 2)

Nessas falas, fica claro que não se trata apenas da distância, mas do meio de transporte. Nesse caso, o barco, utilizado como único meio de locomoção de algumas comunidades, também é um fator que dificulta o acesso das comunidades aos serviços de saúde: "a distância e ter que ir de barco" (Entrevistado 3). A construção desses discursos mostra que ainda existem lacunas no funcionamento das ações de serviços prestados pelo sistema de saúde pública e ratificam a necessidade de efetivação das políticas públicas empregadas pelo SUS no enfrentamento das dificuldades e das desigualdades que ainda persistem no processo assistencial de saúde, incluindo-se discrepâncias entre as regiões urbanas e rurais (Coelho, 2010; Marques et al., 2014).

Então, eu acho que uma das coisas que prejudica muito é a distância e também a questão de eles virem até a unidade no momento em que nós não estamos presentes lá. Por exemplo, nós vamos fazer visita lá de período em período (Entrevistado 6). A falta de profissionais, então, eu acho que lá não vai psicólogo para lá, essas coisas, vai um médico, enfermeiro, um técnico e dentista, é o que vai. Vejo que muitos lá na comunidade, eu acho que tinham uma necessidade de ter um diálogo com o psicólogo também, porque muitos se sentem lá meio que sozinho, como é distante de tudo, aí, às vezes, está longe dos familiares, apesar das comunidades serem bem unidas. (Entrevistado 3)

Mediante as falas múltiplas, os profissionais estabelecem uma relação entre desassistência em saúde e isolamento da comunidade. De acordo com o Painel de Indicadores do SUS, a população afrodescendente, juntamente com os indígenas, 
continua sendo uma das mais desfavorecidas, apresentando níveis mais altos de ruralidade, pobreza, desemprego, analfabetismo e migração, associados com menor acesso aos serviços de saúde e ao saneamento ambiental (Brasil, 2016).

Estudos corroboram as informações anteriores ao afirmar que os problemas de deslocamento decorrentes das grandes distâncias em que se encontra a maioria das comunidades quilombolas são fatores que explicam, pelo menos parcialmente, a menor prevalência de utilização de serviços de saúde (Freitas et al., 2011; Gomes et al., 2013; Santos \& Silva, 2014). Contudo a assistência à saúde no território onde as populações vivem possibilita melhor reconhecimento das necessidades de saúde e dos processos de determinação social da saúde (Costa \& Dimenstein, (2017). Consequentemente, contribui no enfrentamento das iniquidades em saúde, das vulnerabilidades sociais e ambientais, do preconceito e da exclusão social que são historicamente vivenciados por essa população.

\section{Considerações Finais}

Neste estudo buscou-se analisar os sentidos produzidos acerca da assistência em saúde/saúde mental em comunidades quilombolas do Vale do Guaporé por profissionais de saúde. A análise das práticas discursivas dos profissionais aponta que as comunidades em questão são vistas como acolhedoras, receptivas, formadas por pessoas humildes, mas também passivas, submissas, desinteressadas e sem iniciativa.

O estudo também aponta para o isolamento geográfico e o distanciamento teóricoprático da equipe em relação à saúde mental da população negra, além de elementos geradores de exclusão social e construções estereotipadas, que repercutem como condicionantes sociais que impactam negativamente na assistência à saúde nessas comunidades.

Dentre os problemas de saúde mental presentes nas comunidades, destacam-se a depressão e o uso excessivo de bebidas alcoólicas. Entre os repertórios interpretativos, os profissionais referem que a depressão, em muitos casos, está relacionada à perda de um ente querido, e o consumo de álcool parece estar compreendido a partir de questões culturais dessas comunidades. Os resultados também apontam a influência da relação das comunidades com o espaço natural. Nessa conjuntura, as práticas religiosas e o uso de ervas e plantas medicinais retiradas da floresta são utilizados como forma de cuidado em saúde/saúde mental pelos remanescentes quilombolas do Vale do Guaporé. A partir dos repertórios interpretativos relacionados às práticas de saúde próprias das comunidades (chás, curandeiros, religiosidade), os profissionais parecem ter certa dificuldade de integrá-los no processo de atenção à saúde.

Os resultados apontam a importância da implementação de programas de capacitação dos profissionais de saúde, sobretudo em saúde da população quilombola, que deve ser prioritária para uma assistência em saúde que atenda aos princípios do SUS e que sirva de instrumento no enfrentamento dos estigmas e preconceitos que geram desigualdade e exclusão social dessas comunidades. A construção do conhecimento com base nas reflexões dos discursos ora apresentados aponta para a necessidade de efetivar um processo educativo em saúde mental envolvendo os profissionais que compõem a equipe de saúde por meio de capacitação e formação continuada em saúde da população negra para que haja uma reflexão crítica da realidade e dos determinantes sociais que são inerentes a essa população. Além disso, faz-se necessária a viabilização de ações de políticas públicas que melhorem a infraestrutura de acesso às comunidades.

Por fim, espera-se que este estudo possa contribuir como incentivo às reflexões sobre as práticas em saúde nas comunidades quilombolas, bem como em relação aos sentidos produzidos acerca do papel que os profissionais assumem nessa relação. $\mathrm{O}$ estudo apresenta algumas limitações que precisam ser destacadas, especialmente quanto ao número reduzido de profissionais de cada equipe de saúde que participaram da investigação, no entanto as informações obtidas por intermédio deles foram significantes para responder aos objetivos propostos.

\section{Referências}

Almeida, S. L. (2019). Racismo estrutural. São Paulo: Pólen.

Barroso, S. M., Melo, A. P. S., \& Guimarães, M. D. C. (2014). Depressão em comunidades quilombolas no Brasil: Triagem e fatores associados. Revista Panamericana de Salud Pública, 35, 256-263. Link

Brasil. Ministério da Saúde (2004). Saúde mental no SUS: Os centros de atenção psicossocial. Brasília: Ministério da Saúde. Link

Brasil. Ministério da Saúde (2016). Temático Saúde da População Negra. Brasília: Ministério da Saúde, Secretaria de Gestão Estratégica e Participativa. Link 
Brasil. Ministério da Saúde (2017). Política Nacional de Saúde Integral da População Negra: Uma política para o SUS. Brasília: Ministério da Saúde, Secretaria de Gestão Estratégica e Participativa. Link

Cadoná, E., \& Scarparo, H. (2015). Construcionismo social na atenção básica: Uma revisão integrativa. Ciência \& Saúde Coletiva, 20(9), 2721-2730. DOI: 10.1590/1413-81232015209.13552014

Camargo-Borges, C. (2007). O construcionismo social no contexto da estratégia da Saúde da Família: Articulando saberes e práticas. Tese de Doutorado, Programa de Pós-Graduação de Enfermagem em Saúde Pública, Universidade de São Paulo, Ribeirão Preto, SP.

Camargo-Borges, C. (2014). Em busca de uma formação integral e ampliada: construindo práticas colaborativas para o cuidado em saúde. In C. Guanaes-Lorenzi, M. S. Mooscheta, C. M. Corradi-Webster \& L. V. Souza (Eds), Construcionismo social: Discurso, prática e produção do conhecimento (pp. 341-358). Rio de Janeiro: Instituto Noos.

Cardoso, C. S., Melo, L. O. de, \& Freitas, D. A. (2018). Condições de saúde nas comunidades Quilombolas. Journal of Nursing UFPE online, 12(4), 1037-1045. DOI: 10.5205/1981-8963-v12i4a110258p1037-1045-2018

Cardoso, L. G. V., Melo, A. P. S., \& Cesar, C. C. (2015). Prevalência do consumo moderado e excessivo de álcool e fatores associados entre residentes de Comunidades Quilombolas de Vitória da Conquista, Bahia, Brasil. Ciência \& Saúde Coletiva, 20, 809-820. DOI: 10.1590/1413-81232015203.12702014

Carvalho, G. (2013). A saúde pública no Brasil. Estudos avançados, 27(78), 7-26.

Chehuen, J. A., Neto, Fonseca, G. M., Brum, I. V., Santos, J. L. C. T. D., Rodrigues, T. C. G. F., Paulino, K. R., \& Ferreira, R. E. (2015). Política Nacional de Saúde Integral da População Negra: Implementação, conhecimento e aspectos socioeconômicos sob a perspectiva desse segmento populacional. Ciência \& Saúde Coletiva, 20, 1909-1916. DOI: $10.1590 / 1413-81232015206.17212014$

Coelho, I. B. (2010). Democracia sem equidade: Um balanço da reforma sanitária e dos dezenove anos de implantação do Sistema Único de Saúde no Brasil. Ciência \& Saúde Coletiva, 15(1), 171-183. Link

Constituição da República Federativa do Brasil de 1988. (1988). Link

Costa Neto, M. C. D., \& Dimenstein, M. (2017). Cuidado psicossocial em saúde mental em contextos rurais. Temas em Psicologia, 25(4), 1653-1664. DOI: 10.9788/tp2017.4-09pt

Decreto n. 4.887, de 20 de novembro de 2003 (2003). Regulamenta o procedimento para identificação, reconhecimento, delimitação, demarcação e titulação das terras ocupadas por remanescentes das comunidades dos quilombos de que trata o art. 68 do Ato das Disposições Constitucionais Transitórias. Link

Farias, E. D. A., Junior. (2011). Negros do Guaporé o sistema escravista e as territorialidades específicas. RURIS-Revista do Centro de Estudos Rurais-UNICAMP, 5(2), 85-116. Link

Freitas, D. A., Caballero, A. D., Marques, A. S., Hernández, C. I. V., \& Antunes, S. L. N. O. (2011). Saúde e comunidades quilombolas: Uma revisão da literatura. Revista CEFAC, 13(5), 937-943. DOI: 10.1590/S1516-18462011005000033

Gergen, K. J. (1997). Relation and relationships: Soundings in social construction. Cambridge: Harvard University Press.

Gergen, K. J., \& Gergen, M. (2010). Construcionismo social: Um convite ao diálogo. Rio de Janeiro: Instituto Noos.

Gomes, K. D. O., Reis, E. A., Guimarães, M. D. C., \& Cherchiglia, M. L. (2013). Utilização de serviços de saúde por população quilombola do Sudoeste da Bahia, Brasil. Cadernos de Saúde Pública, 29(9), 1829-1842. DOI: 10.1590/0102$311 \mathrm{X} 00151412$ 
Guanaes, C., \& Japur, M. (2008). Contribuições da poética social à pesquisa em psicoterapia de grupo. Estudos de Psicologia, 13(2), 117-124. DOI: 10.1590/S1413-294X2008000200003

Guanaes-Lorenzi, C. (2014). Construcionismo social: Tensões e possibilidades de um movimento em permanente construção. In C. Guanaes-Lorenzi, S. M. Mooscheta, C. M. Corradi-Webster \& V. L. Souza (eds). Construcionismo social: Discurso, prática e produção do conhecimento (pp. 89-104). Rio de Janeiro: Instituto Noos. DOI: 10.1590/S010340142013000200002

Iñiguez, L. (2004). Manual de análise do discurso em ciências sociais. Petrópolis: Vozes.

Lages, S. R. C., Tavares, N. O., Santos, S. V., Carvalho, M. A. S., \& Maciel, L. F. R. (2014). Pesquisas em psicologia social no campo da saúde da população negra no Brasil. Revista de Psicologia da UNESP, 13(1), 1-10. Link

Lei n. 8.080, de 19 de setembro de 1990. (1990). Dispõe sobre as condições para a promoção, proteção e recuperação da saúde, a organização e o funcionamento dos serviços correspondentes e dá outras providências. Link

Lei n. 8.142, de 28 de dezembro de 1990. (1990). Dispõe sobre a participação da comunidade na gestão do Sistema Único de Saúde (SUS) e sobre as transferências intergovernamentais de recursos financeiros na área da saúde e dá outras providências. Link

Marques, A. S., Freitas, D. A., Leão, C. D. A., Oliveira, S. K. M., Pereira, M. M., \& Caldeira, A. P. (2014). Atenção primária e saúde materno-infantil: A percepção de cuidadores em uma comunidade rural quilombola. Ciência \& Saúde Coletiva, 19, 365-371. DOI: 10.1590/1413-81232014192.02992013

Melo, M. F. T., \& Silva, H. P. (2015). Doenças crônicas e os determinantes sociais da saúde em comunidades quilombolas do Pará, Amazônia, Brasil. Revista da Associação Brasileira de Pesquisadores/as Negros/as (ABPN), 7(16), 168-189. Link

Oliveira, A. S. J., Rodrigues, F. E. N., Corrêia, L. S. S., Tavares, M. E., \& Monteiro, T. L. (2011). Quilombolas do Pará: Condições de vulnerabilidade nas comunidades remanescentes de Quilombo. Assis: Triunfal Gráfica e Editora.

Oliveira, R. A., Gellacic, A. S., Zerbinatti, A. S., Souza, F. E. de, \& Aragão, J. A. (2012). Equidade só no papel? Formas de preconceito no Sistema Único de Saúde e o princípio de equidade. Revista Psicología para América Latina, 23, 47-64. Link

Oliveira, S. K. M., Pereira, M. M., Guimarães, A. L. S., \& Caldeira, A. P. (2015). Autopercepção de saúde em quilombolas do norte de Minas Gerais, Brasil. Ciência \& Saúde Coletiva, 20(9), 2879-2890. DOI: 10.1590/1413-81232015209.20342014

Potter, J., \& Wetherell, M. (1987). Discourse and social psychology. London: Sage Publications.

Rasera, E. F., \& Japur, M. (2007). Grupo como construção social. São Paulo: Vetor.

Rasera, E. F., Guanaes-Lorenzi, C., \& Corradi-Webster, C. (2016). Pesquisa como prática social: O pesquisador e os" outros" na produção do conhecimento. Athenea digital: revista de pensamiento e investigación social, 16(2), 325-347. DOI: $10.5565 / \mathrm{rev} /$ athenea. 1839

Santos, A. O. (2018). Saúde mental da população negra: Uma perspectiva não institucional. Revista da Associação Brasileira de Pesquisadores/as Negros/as (ABPN), 10(24), 241-259. Link

Santos, R. C. D., \& Silva, M. S. (2014). Condições de vida e itinerários terapêuticos de quilombolas de Goiás. Saúde e Sociedade, 23(3), 1049-1063. DOI: 10.1590/S0104-12902014000300025

Santos, V. C., Boery, E. N., Pereira, R., Rosa, D. de O. S., Vilela, A. B. A., Anjos, K. F. dos, \& Boery, R. N. S. de O. (2016). Condições socioeconômicas e de saúde associadas à qualidade de vida de idosos quilombolas. Texto \& Contexto Enfermagem, 25(2), e1300015. DOI: 10.1590/0104-07072016001300015 
Sawaia, B. (2014). As artimanhas da exclusão: Análise psicossocial e ética da desigualdade social. Petrópolis: Vozes.

Silva, T. T. (2014). Identidade e diferença: A perspectiva dos estudos culturais. Petrópolis: Vozes.

Silva, J. B. S., Filho, \& Lisboa, A. (2012). Quilombolas: Resistência, história e cultura. São Paulo: IBEP.

Silva, R. A., \& Menezes, J. A. (2016). Reflexões sobre o uso de álcool entre jovens quilombolas. Psicologia \& Sociedade, 28(1), 84-93. DOI: 10.1590/1807-03102015v28n1p084

Silva, V. H F., Dimenstein, M., \& Leite, J. F. (2013). O cuidado em saúde mental em zonas rurais. Mental, 10(19), 267-285. Link

Souza, L. O. C. (2012). Quilombos: Identidade e história. Rio de Janeiro: Nova Fronteira.

Spink, M. J. P. (2013). Psicologia e saúde: Práticas, saberes e sentidos. Petrópolis, RJ: Vozes.

Spink, M. J. P., \& Medrado, B. (2004). Produção de sentidos no cotidiano: Uma abordagem teórico-metodológica para análise das práticas discursivas. In M. J. P Spink (Org.). Práticas discursivas e produção de sentidos no cotidiano: Aproximações teóricas e metodológicas (pp.41-61). 3. ed. São Paulo: Cortez.

Teixeira, M. A. D., \& Xavier, D. F. B. (2018). Santo Antônio do Guaporé: Direitos humanos, conflitos e resistência socioambiental. Revista Direito e Práxis, 9(1), 351-371. DOI: 10.1590/2179-8966/2018/32718

Vieira, A. B. D., \& Monteiro, P. S. (2013). Comunidade quilombola: Análise do problema persistente do acesso à saúde, sob o enfoque da Bioética de Intervenção. Saúde em Debate, 37(99), 610-618. Link

\section{Como citar:}

Batista, E. C., \& Rocha, K. B. (2020). Sentidos Produzidos por Profissionais de Saúde na Atenção a Comunidades Quilombolas do Vale do Guaporé. Revista Subjetividades, 20(Esp 1. Relações Intergrupais: Preconceito e Exclusão Social), e8745. http://doi.org/10.5020/23590777.rs.v20iEsp1.e8745

\section{Endereço para correspondência}

Eraldo Carlos Batista

E-mail: eraldo.cb@hotmail.com

Kátia Bones Rocha

E-mail: katiabonesrocha@gmail.com

Recebido em: $14 / 12 / 2018$

Revisado em: 20/08/2019

Aceito em: 18/11/2019

Publicado online: 20/05/2020 